Przegląd Badań Edukacyjnych Educational Studies Review

ISSN 1895-4308

nr $25(2 / 2017)$, s. 333-343

METODY ZBIERANIA I ANALIZY DANYCH W BADANIACH EDUKACYJNYCH

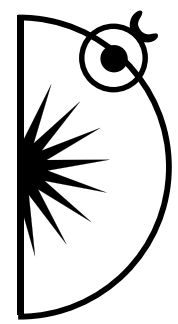

Dariusz Kubinowski

Uniwersytet Szczeciński, e-mail: dkubi@wp.pl

\title{
Możliwości zastosowania społecznych badań internetowych w konstruowaniu wiedzy pedagogicznej
}

DOI: http://dx.doi.org/10.12775/PBE.2014.033

\section{Possibilities of Using Social Internet Research in Constructing Educational Knowledge}

\begin{abstract}
As a result of radical social and cultural transformations with the key role of new media technologies, epistemologies, methodologies and methods of social research have been changed around the academic world. In this worldwide process one of the emergent family of methods is social Internet research.

The main aim of this article is to identify and characterise the nature, key features, and three general genres of social Internet research.

The author presents this elaboration with special intention of stimulating application of Internet research on the field of constructing new educational knowledge as an important need of educational sciences in current Poland. Additionally, we can find in the text the author's interpretation of virtuality understood as a methodological category, and a description of hypermedia research report understood as a new format of scientific elaboration.
\end{abstract}

Key words: Internet research, social research, educational knowledge, virtuality, hypermedia

\section{Wprowadzenie}

Sharlene Nagy Hesse-Biber i Patricia Leavy zauważyły, że „turbulentne” globalne środowisko społeczno-kulturowe początków XXI wieku (coraz bardziej 
nasycane i zmieniane przez technologiczne innowacje) wymusza nieustanne rewidowanie i kreowanie nowych, adekwatnych sposobów badań naukowych, aby możliwe stało się ,nadążanie” za tymi gwałtowanymi przemianami w trakcie konstruowania nowej, adekwatnej wiedzy o człowieku/ludziach i jego/ich świecie/światach. Według tych autorek ciągle powstają wobec tego emergentnie nowe, innowacyjne, elastyczne metody badawcze. Wyrażają one związki między epistemologią (która była znana wcześniej i może być na nowo konstruowana), metodologią, czyli perspektywami teoretycznymi i procedurami badawczymi oraz adekwatną metodyką, wykorzystującą konkretne sposoby badań, zmierzające do rozwiązania nowych problemów badawczych. Tym samym we wszelkich badaniach naukowych, a w szczególności badaniach społecznych istotne jest rozumienie i odzwierciedlenie w procesach poznawczych powiązań między emergencją globalną, dokonującą się w kulturze ludzkiej na całym świecie, emergencją metodologiczną, czyli dostosowywaniem dotychczasowych i kreowaniem nowych metodologii w odniesieniu do owych przemian, a także emergencją metodyczną, która odnosi się do pojedynczego projektu badawczego, realizowanego w konkretnym miejscu i czasie, w oparciu o dostępne, adaptowane i kreowane metody (Hesse-Biber, Leavy, 2008, s. 2-3).

Z kolei Celine-Marie Pascale stwierdziła, że istniejące paradygmaty badawcze nauk społecznych nie są w stanie uchwycić adekwatnie masowej proliferacji mediów XXI wieku oraz ich wielowymiarowego „uwikłania” w różne aspekty życia codziennego ludzi. Tym samym złożoność aktualnej sytuacji kulturowej, warunkowanej w głównej mierze rozwojem technologicznym nowych mediów i ich ekspansją w profilowaniu i kreowaniu przemian cywilizacyjnych, ujawnia dobitnie znaczące ograniczenia poznawcze nauk społecznych (Pascale, 2011, s. 147-149).

Jedną $\mathrm{z}$ emergentnych odpowiedzi epistemologicznych na te przemiany stały się w nauce światowej na przełomie XX i XXI wieku społeczne badania internetowe, ciągle mało znane i rzadko uprawiane na naszym kraju. Celem niniejszego opracowania jest przede wszystkim zwrócenie uwagi na naglącą potrzebę rewizji i uaktualnienia dotychczasowych aksjomatów metodologii nauk społecznych (w tym pedagogicznych) oraz podstaw metodyki badań społecznych (w tym edukacyjnych) z uwzględnieniem wyzwań poznawczych, jakie pojawiły się wraz z rozpowszechnieniem się i zaawansowaniem technologicznym Internetu oraz innych nowych mediów w życiu społecznym na całym świecie. Ponadto chodzi tu o przybliżenie istoty i rodzajów społecznych badań internetowych, z intencją zwrócenia uwagi na ich (ciągle niedostatecznie wykorzystywany w naszym kraju) potencjał w konstruowaniu nowej wiedzy pedago- 
gicznej, niezbędnej w lepszym rozumieniu aktualnej sytuacji wychowawczej/ edukacyjnej dzieci i młodzieży oraz reprezentantów innych grup wiekowych. Dodatkowym motywem przygotowania tego tekstu było również przekazanie zachęty do uprawniania badań internetowych na gruncie rodzimej pedagogiki.

\section{Wirtualność jako kategoria metodologiczna}

Należy zauważyć, że we wszystkich badaniach społecznych - także opartych na relacjach bezpośrednich - kwestia wirtualności znajdowała zawsze swoje odbicie. W świecie zaawansowanego rozwoju Internetu kwestia ta stała się istotną kategorią metodologiczną społecznych badań internetowych.

Jednym z kluczowych jej aspektów jest wirtualna tożsamość badanych. Wobec tego na etapie gromadzenia danych i ich interpretacji uwzględnia się możliwość spotęgowanego, w stosunku do relacji bezpośrednich, manipulowania faktycznymi identyfikacjami.

Status poznawczy badanych zasobów Internetu jako gromadzonych i analizowanych danych zasadniczo różni się od tych pozyskiwanych w kontaktach bezpośrednich. Nakłada to na badacza wymóg uwzględniania tego odmiennego bo wirtualnego statusu w prowadzonych przez niego analizach i interpretacjach.

Wirtualizacja kultury współczesnej doprowadziła do pojawienia się nowego zjawiska społeczno-kulturowego nazwanego „drugim życiem”. Oznacza to, że oprócz egzystencji realnej ,istnieje” równolegle świat wirtualny, kreowany i użytkowany w przestrzeni Internetu. Zmieniło to zasadniczo istotę rzeczywistości społecznej, a tym samym stało się wyznacznikiem przeformułowania podstaw prowadzenia badań społecznych w różnych kontekstach. Fakt pojawienia się i rozwijania przestrzeni wirtualnej funkcjonowania człowieka stał się równocześnie inspiracją do adekwatnej kreatywności metodologicznej.

Internet stworzył ponadto badaczom społecznym dodatkową możliwość pozyskiwania materiału empirycznego za pomocą narządzi badawczych konstruowanych i dystrybuowanych przy jego udziale. Jednakże materiał ten immanentnie posiada również znamiona wirtualności, co wymaga odrębnego jego potraktowania. Wykorzystywanie możliwości technicznych i swoistości komunikacyjnej Internetu $\mathrm{w}$ gromadzeniu danych staje się bowiem istotnym wyznacznikiem ich konstruowania.

Amanda Mitra oraz Elisia Cohen zidentyfikowały i opisały cechy charakterystyczne przekazów wirtualnych zamieszczanych i wtórnie przemieszczających się w Internecie. Pierwszą z nich jest intertekstualność. Przekazy te poprzez funkcjonowanie w cyberprzestrzeni nabierają bowiem nowych znaczeń. 
Drugą jest nielinearność, gdyż konstrukcja tych przekazów nie pozwala na jednoznaczne określenie ich początku i końca. Trzecia to natomiast sprzężenie zwrotne ról czytającego i piszącego. Różne funkcje dostępne w środowisku wirtualnym pozwalają na interaktywne uzupełnianie przekazów przez odbiorców, co prowadzi do ich nieustannych transformacji. Czwartą cechą przekazów wirtualnych jest multimedialność, gdyż przyjmują one przeważnie postać połączonych ze sobą różnych formalnie i treściowo komunikatów medialnych (werbalnych i niewerbalnych). Piątą cechę stanowi globalizacja. Internet pozwala bowiem na rozpowszechnianie przekazów wirtualnych w nieograniczonej skali ogólnoświatowej. I wreszcie szóstą jest ich ulotność. Przekazy wirtualne mają bowiem strukturę dynamiczną, gdyż stale zmieniają się treściowo i formalnie, a na dodatek funkcjonowanie w Internecie może nie być ograniczone czasowo (Mitra, Cohen, 2008, s. 182-192).

Należy w tym miejsci zauważyć, że nie wypracowano dotąd bardziej zaawansowanych odmian społecznych badań internetowych, które niwelowałyby skutki poznawcze wirtualności. Wydaje się, że kwestia ta na swój sposób została częściowo rozwiązana na gruncie paradygmatu konstruktywistycznego badań społecznych. Zasoby Internetu, sam Internet jako medium komunikacji, czy wreszcie dane empiryczne uzyskiwane za pośrednictwem Internetu i e-metod badawczych traktuje się jako konstrukty społeczne, odsuwając na dalszy plan kwestię prawdziwości ich przekazów, i tylko jako takie poddaje się analizie i interpretacji.

\section{Trzy rodzaje społecznych badań internetowych}

Od wielu lat obserwujemy intensyfikację synergii badań społecznych - jakościowych i ilościowych - z nowymi technologiami elektronicznymi, w szczególności z nowymi mediami. W ten sposób metodyka ich uprawiania została znacznie wzmocniona, przede wszystkim w zakresie adekwatnych, coraz doskonalszych instrumentów dokumentowania różnorodnych danych (liczbowych, werbalnych i pozawerbalnych, audialnych, wizualnych i audiowizualnych) oraz wspomagania analizy tych danych za pomocą specjalistycznego oprogramowania komputerowego. Dynamiczny rozwój Internetu stworzył podstawę do wykreowania, a następnie rozwoju społecznych badań internetowych, rozumianych początkowo przede wszystkim jako studiowanie zasobów Internetu. Możliwości techniczne, jakie stwarzają nowe media, przydają się wydatnie w projektowaniu i stosowaniu nowych metod i technik badawczych $\mathrm{w}$ przestrzeni wirtualnej oraz $\mathrm{w}$ badaniu Internetu jako medium komunikacji 
międzyludzkiej [zob. m.in. Jones (red.), 1999; Hine, 2000; Hunsinger, Klastrup, Allen (red.), 2010; Gatson, 2011; Dicks (red.), 2012; Dochartaigh 2012; Kozinets, 2012].

Na podstawie przeglądu dostępnej literatury metodologicznej (w tym wybranych artykułów publikowanych na łamach czasopisma „Internet Research”) przyjmuję, że nazwa „społeczne badania internetowe” obejmuje rodzinę charakterystycznych podejść, metod i technik badawczych, łączących synergicznie różnorodne badania społeczne oraz sposoby poznania procesów i zjawisk społecznych w Internecie, za pośrednictwem Internetu i z pomocą Internetu. Możemy wyróżnić wobec tego trzy rodzaje społecznych badań internetowych.

Po pierwsze jest to badanie i analizowanie wszelkich zasobów Internetu, w tym kultur społeczności wirtualnych, a także wszelkich tekstów kulturowychwerbalnych i pozawerbalnych, zamieszczanych przez ludzi w Internecie, oraz portali społecznościowych, grup dyskusyjnych, for internetowych, czatów, specjalistycznych stron WWW itd., odnoszących się do życia społecznego.

Po drugie jest to poznawanie i interpretowanie Internetu jako medium komunikacji społecznej za pomocą różnych jego możliwości technicznych, jak również badanie i rozumienie relacji między społecznymi światami realnymi i wirtualnymi ludzi w procesie interakcji.

I wreszcie po trzecie jest to wykorzystywanie możliwości Internetu (w tym różnych technologii hipertekstualnych i hipermedialnych) w adaptowaniu oraz kreowaniu metod i technik badań społecznych w synergii z nowymi mediami, $\mathrm{w}$ procesie postępowania badawczego na wszystkich jego etapach.

Jednym z pierwszych charakterystycznych podejść badawczych z tej rodziny była etnografia wirtualna, inaczej nazywana etnografią Internetu, cyberetnografią czy netnografią (Kozinets 2012). Polega ona na wykorzystaniu filozofii i metodyki badań etnograficznych w świecie Internetu, co znacznie poszerzyło możliwości podejmowania nowych tematów badawczych, także o zasięgu globalnym. Etnograf w tym przypadku porusza się w świecie wirtualnym, korzystając z dróg i zasobów hipermedialnego środowiska, a przedmiotem jego badań stają się „cyberkultury tubylców” wybranych grup społecznościowych.

Popularną techniką społecznych badań internetowych stała się e-ankieta, czyli ankieta zamieszczana w Internecie bądź rozsyłana za pomocą Internetu, do anonimowych respondentów. Jak każda technika badawcza posiada ona swoje zalety i wady. Zaletą jest niewątpliwie możliwość szybkiego i taniego przeprowadzenia masowych badań sondażowych na niespotykaną dotąd skalę, pod warunkiem jednak, że zakres podejmowanych kwestii będzie zminimalizowany, a ich formuła zasadniczo ograniczona do pytań zamkniętych. Wadą takich 
badań ankietowych jest ich generalna niereprezentatywność, a to ze względu na przypadkowość doboru próby oraz zwiększone ryzyko zasadniczego manipulowania udzielaniem rzetelnych odpowiedzi. Wyniki uzyskane tą drogą nie mogą wobec tego stanowić podstawy do konstruowania zaawansowanej wiedzy naukowej, choć mogą przynosić istotne korzyści poznawcze.

E-wywiad polega na prowadzeniu przez badacza korespondencji z badanym za pośrednictwem poczty elektronicznej. Tożsamość badanego przeważnie jest znana badaczowi z kontaktów bezpośrednich. Po uzyskaniu zgody na udział w badaniach, analityk przesyła badanemu kilka wstępnych pytań, a następnie po otrzymaniu jego odpowiedzi dalsze, bardziej pogłębiające zasadniczy temat badań i szczegółową problematykę. Wywiady takie oszczędzają czas i środki badacza, gdyż nie wymagają kosztownego przemieszczania się w przestrzeni, żmudnych transkrypcji, umożliwiają równoległe prowadzenie korespondencji $\mathrm{z}$ wieloma badanymi. Jednak nie pozwalają na udokumentowanie przekazów werbalnych i niewerbalnych wyzwalanych wyłącznie w trakcie bezpośredniej rozmowy i presji natychmiastowej reakcji na stawiane pytania.

Innymi jeszcze sposobami społecznych badań internetowych są badania fokusowe online oraz wideokonferencje. Grupy fokusowe online tworzone w celach badawczych mogą służyć prowadzeniu synchronicznych lub asynchronicznych dyskusji z udziałem wielu osób. Sesje synchroniczne realizowane są za pośrednictwem czatów albo konferencji online, w tym audio- i wideokonferencji. Natomiast sesje asynchroniczne odbywają się, między innymi, za pośrednictwem poczty elektronicznej i list dyskusyjnych.

Niekiedy w badaniach Internetu jako medium komunikacji międzyludzkiej wykorzystuje się prowokację badawczą. Może być ona zastosowana przykładowo do rozpoznania patogennego problemu zawierania związków intymnych w Sieci. Badacz/badaczka, wykorzystując internetowe możliwości ukrycia własnej tożsamości, przybiera kilka fałszywych nicków i nawiązuje oraz rozwija w celach badawczych kontakty z osobami zainteresowanymi nawiązaniem znajomości. Uzyskany tą drogą materiał empiryczny jest przeważnie bardzo wartościowy poznawczo. Zaznaczyć jednak należy, że wszelkie prowokacje badawcze tego rodzaju niosą za sobą poważne zastrzeżenia natury etycznej oraz mogą stanowić realne niebezpieczeństwo dla badacza/badaczki. Stąd uzasadnienie do podjęcia takich procedur badawczych musi być bardzo przekonujące.

W ramach społecznych badań internetowych rozwinęly się także analizy blogów. Blog jest to rodzaj osobistego pamiętnika prowadzonego na stronie internetowej. W zależności od ich rodzajów zawierać może różnorodne przekazy werbalne i niewerbalne (fotografie, filmy, muzykę itd.). Poza tym nieodłącznym 
komponentem tego rodzaju badań jest dokumentowanie i analizowanie komentarzy internautów. Jednakże należy pamiętać, że status poznawczy treści i form tego rodzaju pamiętników odbiega zasadniczo od przekazów tradycyjnych dzienników intymnych, pisanych wyłącznie dla siebie i ukrywanych przed postronnymi, niepożądanymi czytelnikami. W przypadku blogów mocno manifestuje się tu kwestia wirtualności, gdyż wspomnienia i wypowiedzi ich autorów intencjonalnie są tak przygotowane i zamieszczane w Internecie, aby zdobyć jak największą liczbę czytelników oraz intensywnie stymulować ich do zamieszczania swoich komentarzy. Niemniej jednak badanie tego rodzaju zasobów Internetu może przynosić dziś istotne korzyści poznawcze z uwagi na ogromną popularność prowadzenia własnych blogów przez reprezentantów różnych grup społecznych.

\section{Potencjał społecznych badań internetowych a potrzeby konstruowania nowej wiedzy pedagogicznej}

W związku z rozpowszechnieniem się Internetu (wraz z innymi nowymi mediami) oraz wydatnym zwiększeniem jego znaczenia w życiu społecznym i kulturze ludzkiej, zmieniły się zasadniczo konteksty realizowanych aktualnie procesów edukacyjnych/wychowawczych. Powstało więc ogromne zapotrzebowanie na konstruowanie nowej wiedzy pedagogicznej, opartej na rezultatach prowadzonych studiów i badań z zastosowaniem adekwatnych metod poznania naukowego. Jedną z istotnych dróg tworzenia takiej wiedzy może okazać się szersze i bardziej zaawansowane wykorzystanie w pedagogice współczesnej możliwości społecznych badań internetowych, w trzech wyżej scharakteryzowanych ich zakresach. Chodzi zatem o badanie różnorodnych zasobów Internetu odnoszących się wprost do problematyki wychowawczej/edukacyjnej bądź stanowiących istotny jej kontekst społeczno-kulturowy. Ponadto istotne jest pedagogiczne badanie Internetu jako medium komunikacji społecznej i tym samym podejmowanie tematów dotyczących edukacyjnych/wychowawczych jej kontekstów. I wreszcie niezbędne zdaje się adaptowanie charakterystycznych podejść, metod i technik społecznych badań internetowych do potrzeb realizowanych projektów badań pedagogicznych dotyczących różnej problematyki, nie tylko związanej z zasobami czy funkcjonowaniem Internetu.

Spróbujmy wskazać kilka istotnych tropów poznawczych, które można podejmować w ramach szeroko rozumianych internetowych badań pedagogicznych.

Internet staje się narzędziem ilościowego i jakościowego rozwoju kultury, dzięki niemu pojawiają się nowe formy twórczości, w tym kreacje multimedialne i hipermedialne. Przyczynia się niewątpliwie do niespotykanej dotąd 
demokratyzacji uczestnictwa w kulturze oraz technologicznego wzmocnienia procesu upowszechniania kultury, w tym kultury „wysokiej”, dziedzictwa kulturowego i tradycji. Dzięki niemu wiele milionów ludzi na całym świecie uzyskuje możliwość bezpośredniego przeżywania ważnych wydarzeń historycznych, uczestniczenia w życiu religijnym, kulturalnym, poznawania innych ludzi i społeczeństw, za sprawą powszechnie dostępnych komputerów osobistych i innych urządzeń telekomunikacyjnych $\mathrm{z}$ łatwą możliwością podłączenia do Sieci niemalże w każdym miejscu. Postępujący rozwój Internetu przyczynia się do usprawnienia funkcjonowania społeczeństwa obywatelskiego, uruchamia pokłady wielkiej aktywności w skali globalnej, między innymi poprzez różnorodne grupy społecznościowe, tworzy niewyobrażalną - jeszcze nie tak dawno - przestrzeń natychmiastowego dostępu do ogromnych zasobów wiedzy na każdy temat, przy minimalnym nakładzie środków i czasu.

Wirtualizacja kultury za sprawą rozpowszechnienia Internetu i innych nowych mediów zmienia jednak zasadniczo komunikację międzyludzką. Popularność komunikacji pośredniej wywołuje zmiany w języku, wynikające zarówno z aspektów technicznych, jak i komercyjnych, czego rezultatem jest między innymi potrzeba maksymalnej skrótowości form przekazu. Anonimowość cyberprzestrzeni daje z jednej strony możliwość unikania odpowiedzialności za słowa, czyny, postawy, a z drugiej jednak strony może prowadzić do zaburzeń tożsamościowych i skrajnej indywidualizacji światopoglądu. Stwarza ponadto pokusę zachowań społecznie niepożądanych czy wręcz działalności przestępczej, zarówno w roli odbiorcy, jak i nadawcy przekazów czy uczestnika różnego rodzaju procederów. Takie zjawiska, jak ogólnodostępne darmowe strony pornograficzne, aktywność pedofilów czy specjalne komunikatory służące do umawiania się na „okazjonalny seks” stanowią dziś nieodłączny element cyberkultury. Rodzice spokojni o własne dziecko, które siedzi w ciszy przed komputerem w swoim pokoju, często nie zdają sobie w pełni sprawy, jakie zagrożenia się z tym wiążą. Samotność dziecka w Sieci stała się również aktualnym i istotnym problemem pedagogicznym.

\section{Hipermedialny raport badawczy}

Synergia sztuki i nowych mediów, rozwój humanistyki cyfrowej oraz rozpowszechnienie się multimedialnych publikacji naukowych on-line (głównie czasopism) doprowadziły do pojawienia się nowego formatu opracowania badawczego w postaci raportu hipermedialnego. Multimedia i hipermedia stają się bardzo często integralną częścią różnych badań społecznych w poszczególnych 
fazach procesu badawczego: badań terenowych i generowania danych, rejestracji , analizy i interpretacji oraz ich reprezentacji, a następnie scalenia w raporcie multimedialnym (najczęściej przybierającym postać strony WWW), który pozwala na globalne rozpowszechnianie wyników badań za pośrednictwem Internetu (Dicks, Mason, 2008, s. 586-595).

Wykreowane przez badacza specjalnie na potrzeby realizowanego projektu środowisko hipermedialne, użytkowane przez niego od początku badań i wielokrotnie modyfikowane zgodnie z zasadami przyjętej metodologii, staje się jednocześnie wielowymiarową przestrzenią przeróżnych przekazów poznawczych powiązanych ze sobą hiperłączami. Opracowanie takie może być rozpowszechniane elektronicznie oraz tak zaprojektowane, aby jego odbiorcy mogli sami wybierać i rozwijać drogi subiektywnej interpretacji. Użytkownik takiego raportu staje się nawigatorem poruszającym się po sieci łączącej dane, komentarze, ilustracje, reprezentacje, przypisy, cytaty z literatury, twierdzenia, odnośniki internetowe itd. Tworzy się zintegrowany system umożliwiający równoczesne gromadzenie i analizowanie danych, zarządzanie nimi, przygotowywanie opracowania i korzystanie z niego, a także ewentualne jego rozwijanie. Hipermedialne raporty badawcze są przeważnie celowo otwarte na nowe interpretacje użytkowników, tworząc podstawę do rozwijania współpracy z osobami zainteresowanymi projektem i jego rezultatami. Jak się wydaje, tego rodzaju opracowania badawcze mogą niebawem zastąpić monopol książek i czasopism drukowanych, które tak wielu możliwości sieciowego, multimedialnego i hipermedialnego prezentowania wyników badań naukowych nie posiadają (Kubinowski, 2010, s. 293-295).

\section{Podsumowanie}

Christine Hine, autorka zajmująca się od wielu lat metodologią badań internetowych w naukach społecznych, zaprezentowała ambiwalentne stanowisko w kwestii ich innowacyjnego statusu naukowego. Uzasadniała to następująco:

„Mimo że dostrzegana nowość Internetu zachęciła wielu, w tym badaczy społecznych, do zaangażowania się i poważnego potraktowania perspektywicznego rozwoju nowego zjawiska, to doświadczenie często wskazywało na większe zakorzenienie, to znaczny wymieszanie kontynuacji starych tradycji z zaledwie powiewem nowości. Aby być przydatnymi źródłami wiedzy, sposoby użytkowania Internetu i metody badań internetowych muszą stać się znaczącymi w kontekście życia codziennego i poszczególnych dyscyplin akademickich. Emergentna praktyka badań 
internetowych wymaga poważnego przejęcia się tym, że coś nowego może istotnie zaistnieć, ale wymaga rewizji tradycji dyscyplinarnych, które ugruntowują nasze myślenie, oraz stworzenia przestrzeni, w ramach której będą przeprowadzane debaty na temat metodologicznej adekwatności" (Hine, 2008, s. 538).

Przemiany cywilizacyjne, kulturowe i społeczne XXI wieku, w dużej mierze będące konsekwencją rozwoju nowych technologii w zakresie komunikacji elektronicznej, stanowią istotne wyzwanie dla metodologii i praktyki badawczej w naukach społecznych, w tym pedagogicznych. Większość aktualnych badaczy była socjalizowana w odmiennych warunkach kulturowych. Mimo intensywnych wysiłków nie są oni przeważnie w stanie osiągnąć poziomu rozumienia funkcjonowania Internetu i innych nowych mediów, który posiadają najmłodsze pokolenia od wczesnego dzieciństwa oswajane z najnowszymi technologiami informacyjnymi. Mimo to metodolodzy i badacze społeczni nie mają innego wyjścia, jak tylko otworzyć się koncepcyjnie i poznawczo na całokształt doświadczeń komunikacji społeczno-kulturowej współczesnego człowieka oraz dążyć do wypracowania i efektywnego stosowania adekwatnych metod ich poznawania w celu konstruowania nowej, niezmiernie pożądanej z naukowego i praktycznego punktu widzenia wiedzy humanistycznej, społecznej oraz pedagogicznej etc.

\section{Bibliografia}

Dicks B., Mason B. (2008). Hypermedia methods for qualitative research. W: S. N. Hesse-Biber, P. Leavy (red.). Handbook of Emergent Methods. NewYork - London: The Guilford Press.

Dicks (red.), (2012). Digital qualitative research methods. t. 1-4, Los Angeles-London-New Delhi-Singapore-Washington: Sage Publications.

Dochartaigh N. O. (2012). Internet Research Skills. Los Angeles-London-New Delhi-Singapore-Washington: Sage Publications.

Gatson S. N. (2011). The Methods, Politics, and Ethics of Representation in Online Ethnography. W: N. K. Denzin, Y. S. Lincoln (red.). The Sage Handbook of Qualitative Research - Fourth Edition, Los Angeles-London-New Delhi-Singapore-Washington: Sage Publications.

Hesse-Biber S., Leavy P. (2008). Pushing on the Methodological Boundaries. The Growing Need for Emergent Methods within and across the Disciplines. W: S. N. Hesse-Biber, P. Leavy (red.). Handbook of Emergent Methods. New York-London: The Guilford Press. 
Hine Ch. (2000). Virtual Ethnography. London-Thousand Oaks-New Delhi: Sage Publications.

Hine Ch. (2008). Internet Research as Emergent Practice. W: S. N. Hesse-Biber, P. Leavy (red.). Handbook of Emergent Methods. New York-London: The Guilford Press.

Hunsinger J., Klastrup L., Allen M. M. (red.), (2010). International Handbook of Internet Research. London: Springer.

Jones S. (red.), (1999). Doing Internet Research. Critical Issues and Methods for Examining the Net. Thousand Oaks-London-New Delhi: Sage Publications.

Kozinets R. V. (2012). Netnografia. Badania etnograficzne on-line. Warszawa: Wydawnictwo Naukowe.

Kubinowski D. (2010). Jakościowe badania pedagogiczne - filozofia, metodyka, Ewaluacja. Lublin: Wydawnictwo Uniwersytetu Marii Curie-Skłodowskiej.

Mitra A., Cohen E. (1999). Analyzing the Web - Directions and Challenges. W: Jones S. (red.). Doing Internet Research. Critical Issues and Methods for Examining the Net. Thousand Oaks-London-New Delhi: Sage Publications. 
